\title{
Modelling the change in the oxidation coefficient during the aerobic degradation of phenol by acclimated activated sludge
}

\author{
Cintia C Lobo', Nora C Bertola' and Edgardo M Contreras ${ }^{2,3^{*}}$ \\ 'Centro de Investigación y Desarrollo en Criotecnología de Alimentos (CIDCA) - CONICET - Fac. de Cs. Exactas - UNLP. 47 y 116 (B1900AJJ) \\ - La Plata, Argentina \\ ${ }^{2}$ Fac. de Ingeniería - UNLP. 47 y 1 (B1900AJJ) - La Plata, Argentina \\ ${ }^{3}$ Instituto de Investigaciones en Ciencia y Tecnología de Materiales (INTEMA) - CONICET - Av. Juan B. Justo 4302 (7600) Mar del Plata, Argentina
}

\section{ABSTRACT}

In this work the aerobic degradation of phenol by acclimated activated sludge was studied. Results demonstrate that while the phenol removal rate by acclimated activated sludge follows the Monod model, the oxygen uptake rate obeys a Haldanetype equation. The phenol oxidation coefficient obtained at different intial phenol concentrations ranged from 1.9 to $2.6 \mathrm{~mol}$ $\mathrm{O}_{2} \cdot \mathrm{mol}^{-1}$ phenol. A mathematical model based on a simplified version of the catalytic mechanism of the enzyme phenol 2-monooxygenase was developed to predict transient phenol concentrations and oxygen requirements by phenol-acclimated activated sludge in batch reactors under different initial phenol concentrations. The proposed model not only adequately represents the experimental results of the present paper, but also those reported by other authors. Particular cases of the proposed model are discussed.

Keywords: oxygen uptake rate; phenol; biodegradation; biokinetic model; respirometry

\section{INTRODUCTION}

Phenolic compounds are considered to be a major group of hazardous environmental pollutants. Several industries, such as petroleum processing plants, oil refineries, coke oven and pharmaceuticals, generate large amounts of phenolic wastewaters (Lepik and Tenno, 2011; Pramparo et al., 2012). Phenol is used as an intermediate in the production of phenolic resins, which are used in the plywood, adhesive, construction, automotive and appliance industries, in the production of synthetic fibres and for epoxy resin precursors. Besides, phenolic compounds are naturally present in some foodstuffs, in human and animal wastes, and in decomposing organic material, and are produced from the metabolism of proteins (Lin and Juang, 2009).

Phenols can be removed from industrial effluents by several physicochemical methods. Separation technologies include distillation, liquid-liquid extraction, adsorption over activated carbons and polymeric and inorganic adsorbents, membrane pervaporation and membrane-solvent extraction. Destruction technologies such as non-catalytic, supercritical and catalytic wet air oxidation, ozonation, non-catalytic, catalytic and enzymatic peroxide wet oxidation, electrochemical and photocatalytic oxidation have also been studied. As a general rule, all these treatments are usually complex and very expensive; for these reasons, biological methods are preferred (Busca et al., 2008).

Many aerobic bacteria and mixed cultures are capable of degrading aromatic compounds as the sole carbon and energy source (El-Naas et al., 2009; Banerjee and Ghoshal, 2010). Batch and semi-continuous systems with suspended or immobilised

\footnotetext{
To whom all correspondence should be addressed.

Iiin +54 2234816600 (Int. 242);

e-mail: edgardo.contreras@ing.unlp.edu.ar

Received 20 January 2013; accepted in revised form 17 December 2013.
}

biomass were used to study phenol degradation kinetics (Orupold et al., 2001; Nuhoglu and Yalcin, 2005; Tziotzios et al., 2005). The most used model to describe the dependence of biomass growth, phenol and oxygen consumption rates on a self-inhibitory substrate, such as phenol, is the Haldane equation with a constant yield (Christen et al., 2012; Pramparo et al., 2012). Although the Haldane model can be derived from an enzymatic mechanism, not all the enzymes involved in phenol metabolism can be represented by this mechanism. In particular, the first step in the aerobic biodegradation of phenol comprises the oxidation of phenol to catechol by the enzyme phenol 2-monooxygenase (PH2MO). The catalytic mechanism of $\mathrm{PH} 2 \mathrm{MO}$ is complex, involving FAD and 3 substrates (molecular oxygen, phenol and NADPH) (Enroth et al., 1998).

Due to the lack of fit of the traditional approach (e.g., the Haldane equation with a constant yield), several authors (Feitkenhauer et al., 2001; Nuhoglu and Yalcin, 2005; BenYoussef and Vázquez-Rodríguez, 2011) have proposed different modifications to the traditional model. However, those models were developed on an empirical base, i.e. the study of phenol degradation and biomass growth kinetics and then the fitting of an appropriate mathematical model to the obtained results. Additionally, most studies concerning the aerobic degradation of phenol have been performed using pure cultures, low concentration ranges of phenol, or even a single initial concentration of phenol. In this sense, further investigation is necessary to understand phenol biodegradation under more realistic conditions, especially in biological wastewater treatment systems where the concentration of phenol can vary over a wide range (Alcocer et al., 2007; Banerjee and Ghoshal, 2010; El-Naas et al., 2010).

Knowledge of microbial substrate consumption kinetics is important for accurate prediction of the quality of the treatment process effluent. One key feature is the relationship between phenol concentration and the rates of substrate and oxygen consumption (Kumar et al., 2005; Nuhoglu and Yalcin. 
2005). While the substrate consumption rate determines the size of bioreactors, knowledge of the oxygen uptake rate associated with phenol degradation is crucial to an appropriate design of aeration devices. Taking into account that, in a typical activated sludge wastewater treatment plant, aeration costs represent approximately $45 \%$ of the total operative cost (e.g. energy for aeration, pumping, and sludge treatment) (Vanrolleghem and Gillot, 2002), accurate kinetic models help engineers to optimise operational conditions in order to meet discharge requirements, minimising operational costs. For these reasons, in this work a mathematical model based on a simplified version of the catalytic mechanism of $\mathrm{PH} 2 \mathrm{MO}$ was developed to predict transient phenol concentrations and oxygen requirements by phenol-acclimated activated sludge in batch reactors under different initial phenol concentrations.

\section{EXPERIMENTAL}

\section{Chemicals and reagents}

Phenol (loose crystals, > 99\%) was obtained from Sigma (St. Lois, MO, USA). All inorganic salts were commercial products of reagent grade from Anedra (San Fernando, Argentina). Dehydrated cheese whey was from Food S.A. (Villa Maipú, Argentina).

\section{Acclimation of activated sludge to phenol}

Activated sludge used in this study was cultured in a laboratory-scale $(2.5 \ell)$ cylindrical semicontinuous fill and draw reactor. Aeration was provided at the bottom of the reactor through an air-stone using 2 air pumps at $2 \ell \cdot \mathrm{min}^{-1}$; dissolved oxygen (DO) concentration was maintained above $4 \mathrm{mg} \cdot \ell^{-1}$. Phenolacclimated activated sludge was obtained as follows: Initially, the reactor was fed with a model wastewater of the dairy industry (Lobo et al., 2013), dehydrated cheese whey 1000 $\mathrm{mg},\left(\mathrm{NH}_{4}\right)_{2} \mathrm{SO}_{4} 940 \mathrm{mg}, \mathrm{K}_{2} \mathrm{HPO}_{4} 500 \mathrm{mg}$ and $\mathrm{KH}_{2} \mathrm{PO}_{4} 250 \mathrm{mg}$. All components were diluted in $1 \ell$ of tap water. The hydraulic retention time was $80 \mathrm{~h}$ and a solids retention time of 30 days was maintained by direct wastage. After 70 days of operation, the model wastewater was replaced by a culture medium with phenol as the sole carbon-limiting source (Nuhoglu and Yalcin, 2005): $\left(\mathrm{NH}_{4}\right)_{2} \mathrm{SO}_{4} 226 \mathrm{mg} \cdot \ell^{-1}, \mathrm{~K}_{2} \mathrm{HPO}_{4} 500 \mathrm{mg} \cdot \ell^{-1} \mathrm{KH}_{2} \mathrm{PO}_{4}$ $250 \mathrm{mg} \cdot \ell^{-1}, \mathrm{MgSO}_{4} \cdot 7 \mathrm{H}_{2} \mathrm{O} 25.2 \mathrm{mg} \cdot \ell^{-1}, \mathrm{MnSO}_{4} \cdot \mathrm{H}_{2} \mathrm{O} 2.52$ $\mathrm{mg} \cdot \ell^{-1}, \mathrm{CaCl}_{2} 2 \mathrm{mg} \cdot \ell^{-1}, \mathrm{FeCl}_{3} 1.2 \mathrm{mg} \cdot \ell^{-1}$, phenol $300 \mathrm{mg} \cdot \ell^{-1} \cdot \mathrm{pH}$ was adjusted to $7.0 \pm 0.05$ by adding a few drops of concentrated solutions of $\mathrm{NaOH}$ or $\mathrm{HCl}$. During this phase the solids retention time was increased to 45 days in order to prevent biomass washout. The reactor was monitored periodically by measurements of total suspended solids (TSS), soluble chemical oxygen demand $(s C O D)$ and soluble COD consumption rate $\left(R_{C O D}\right)$. Biomass was considered acclimated to phenol when the specific $s C O D$ consumption rate $\left(q_{C O D}=R_{C O D} / T S S\right)$ was approx. constant for at least 2 weeks.

During several fill and draw cycles, total phenol (TPh) and DO were also measured as a function of the cycle time. In these cases, before the addition of phenol, the oxygen mass transfer coefficient $\left(k_{L} a\right)$ was obtained using a non-steady state procedure (Ros, 1993). The oxygen uptake rate associated with phenol consumption $\left(R_{\mathrm{O} 2}\right)$ was calculated from the DO mass balance in the reactor:

$$
R_{O 2}=k_{L} a\left(C_{E}-C\right)-\frac{d C}{d t}
$$

where:

$C_{E}$ is the DO concentration in equilibrium with respiration in the absence of substrate

$C$ is the instantaneous DO concentration

The amount of oxygen consumed $(O C)$ during the phenol oxidation was calculated as follows:

$$
\mathrm{OC}=\int_{0}^{t} R_{\mathrm{O} 2} d t
$$

The overall oxidation coefficient $\left(Y_{\mathrm{O} / \mathrm{S}}\right)$, which represents the amount of oxygen consumed per unit of substrate (phenol) oxidised, was calculated as the ratio $O C_{m} / S_{0}$, where $O C_{m}$ is the maximum amount of oxygen consumed and $S_{0}$ is the initial phenol concentration $\left(\mathrm{mg} \cdot \ell^{-1}\right)$.

\section{Effect of the initial phenol concentration on the biodegradation kinetics}

The effect of initial phenol concentration on phenol degradation kinetics by phenol-acclimated activated sludge was assessed using an open (flowing gas/static liquid) respirometer. Before performing the assays, activated sludge samples were washed 3 times with phosphate buffer $(15 \mathrm{mM}, \mathrm{pH}=7)$ and re-suspended to a final volume of $500 \mathrm{~m} \ell$ using the above-mentioned buffer. Then, $0.5 \mathrm{~m} \ell$ micronutrient solutions were added (Contreras et al., 2011). Washed activated sludge samples were poured into the respirometer, which consists of a 500 -m $\ell$ working volume reactor with temperature control $\left(25 \pm 0.5^{\circ} \mathrm{C}\right)$. The sample was stirred with a magnetic stir-bar and was aerated continuously by an air pump. Air was set to a stable flow rate $\left(1.0 \ell \cdot \mathrm{min}^{-1}\right)$ using a high precision rotameter (Bruno Schilling model MB $60 \mathrm{~V}$, Argentina), and DO concentration as a function of time was recorded. Oxygen mass transfer coefficient of the respirometer $\left(k_{L} a\right)$ and $R_{\mathrm{O} 2}$ values were calculated as described in the previous section. In these experiments the biomass concentration was $0.7 \mathrm{~g} \cdot \ell^{-1}$ TSS and tested initial phenol concentration $\left(S_{0}\right)$ ranged from 0.53 to $5.3 \mathrm{mM}$.

\section{Analytical procedures}

Total suspended solids (TSS) were used as a measure for the biomass concentration ( $\left.X, \mathrm{~g} \cdot \ell^{-1} T S S\right)$. Duplicate biomass measurements were performed to reduce experimental errors; average and maximum relative errors for TSS were $4 \%$ and $13 \%$, respectively. Dissolved oxygen (DO) concentration was measured using a polarographic DO probe YSI (model 5739). DO data were acquired by a personal computer interfaced to a DO monitor YSI (model 58). Soluble COD $(s C O D)$ was determined as follows: $3 \mathrm{ml}$ of culture samples were centrifuged for $5 \mathrm{~min}$ at $13000 \mathrm{r} \cdot \mathrm{min}^{-1}$ (Eppendorf 5415C); then, COD of the supernatant was determined using a commercial test (Hach). Sample digestion $\left(2 \mathrm{~h}, 150^{\circ} \mathrm{C}\right)$ was performed in a Hach COD Reactor 45600; a Hach DR 2000 photometer was used for the absorbance determination step. Total phenol (TPh) concentration of the supernatant was measured using the 4-aminoantipyrine (4-AAP) method (Vazquez-Rodriguez et al., 2006). This method uses 2 reagents, 4 -AAP $(20.8 \mathrm{mM}$ of 4 -AAP in 0.25 $\mathrm{M} \mathrm{NaHCO}_{3}$ ) and ferricyanide $\left(83.4 \mathrm{mM}_{3}\right.$ of $\mathrm{K}_{3} \mathrm{Fe}(\mathrm{CN})_{6}$ in 0.25 $\mathrm{M} \mathrm{NaHCO}_{3}$ ), as colour-generating substrates when combined with phenolic compounds. Coloured complexes were measured at $510 \mathrm{~nm}$ in a Hach DR 2000 spectrophotometer. Calibration curves were performed periodically using phenol as the reference compound. 


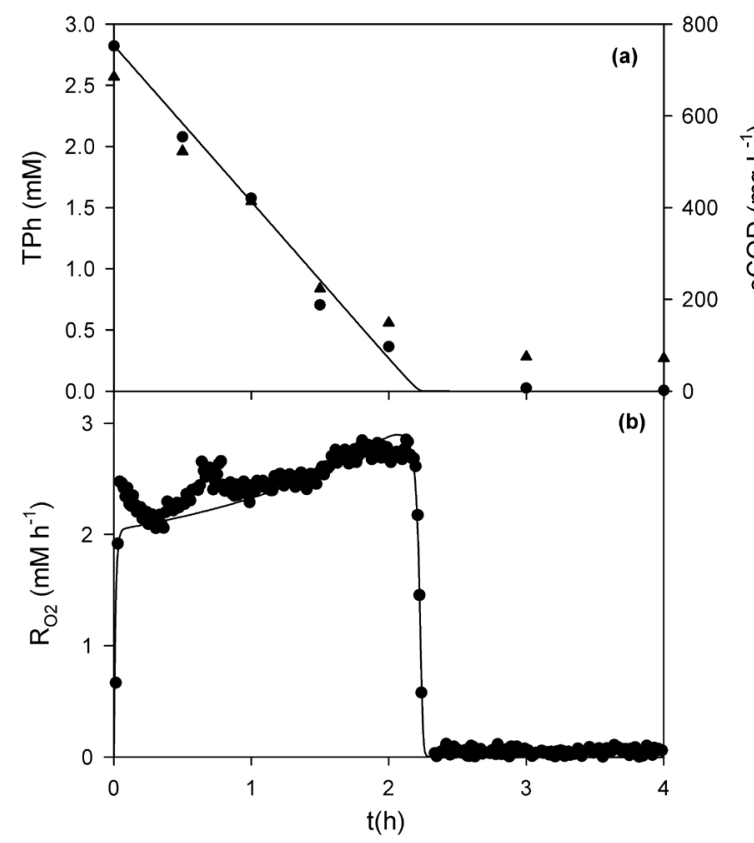

Figure 1

Example of (a) total phenols (TPh, $\bullet$ ), soluble COD (sCOD, $\mathbf{\Delta})$ and (b) oxygen uptake rate $\left(R_{o y} \bullet\right.$ ) as a function of time during a fill and draw cycle. Solid lines indicate the results obtained by the proposed model (Eqs. (12) and (19)) using the coefficients shown in Table 1.

In this example the biomass concentration was $1.8 \mathrm{~g} \cdot \ell^{-1} \mathrm{TSS}$.

\section{Estimation of the model coefficients and dynamic simulations}

Coefficients of the mathematical model proposed in this work and the dynamic simulations were performed using the software package Gepasi 3. The routine LSODA (Livermore Solver of Ordinary Differential Equations) was selected to integrate the system of differential equations of the proposed model. Multistart Optimisation algorithm (with Levenberg-Marquardt local optimisation) was selected to fit the proposed model to the experimental data. In order to reduce fitting errors of the adjustable coefficients, initial concentrations were adjusted within $\pm 5 \%$ of their measured values. This procedure takes into account the degree of uncertainty in the initial conditions due to analytical errors. To describe the biological startup phenomenon, a first-order correction factor was included (Contreras et al., 2008).

\section{RESULTS AND DISCUSSION}

\section{Phenol consumption and oxygen uptake by phenol- acclimated activated sludge}

Figure la shows an example of total phenol (TPh) and soluble COD $(s C O D)$ concentration profiles during a fill and draw cycle with phenol. Both TPh and $s C O D$ exhibited a linear decrease up to phenol depletion at $t=2.2 \mathrm{~h}$; within this interval, removal rates of $T P h$ and $s C O D$ were $1.26 \mathrm{mM} \cdot \mathrm{h}^{-1}$ and $274 \mathrm{mg} \cdot \ell^{-1} \cdot \mathrm{h}^{-1}$, respectively. Figure la shows that $T P h$ removal is linear until its depletion, which corresponds to a constant removal rate of $T P h$. The oxygen uptake rate associated with phenol consumption $\left(R_{\mathrm{O}_{2}}\right)$ is shown in Fig.1b. After a short start-up period, $R_{\mathrm{O} 2}$ increased from 2 to $3 \mathrm{mM} \cdot \mathrm{h}^{-1}$ as a function of time; then, $R_{\mathrm{O} 2}$ decreased to values close to zero due to phenol depletion. Taking into account that during this experiment the biomass

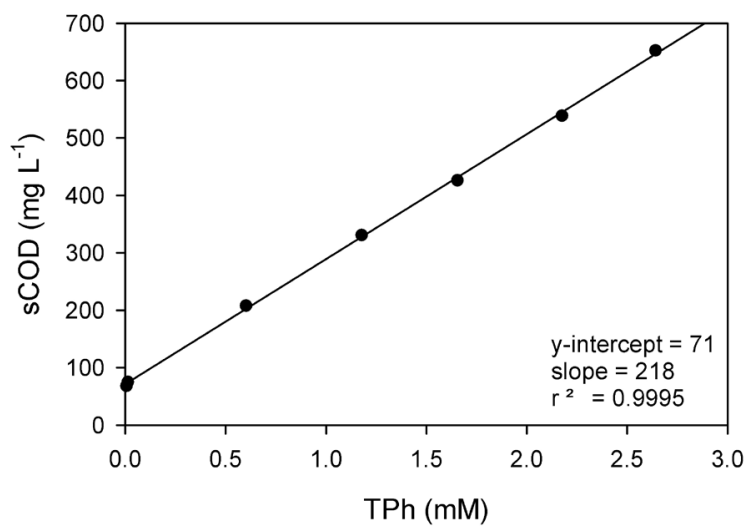

Figure 2

Soluble COD (sCOD) as a function of total phenol (TPh) corresponding to the example depicted in Fig. 1.

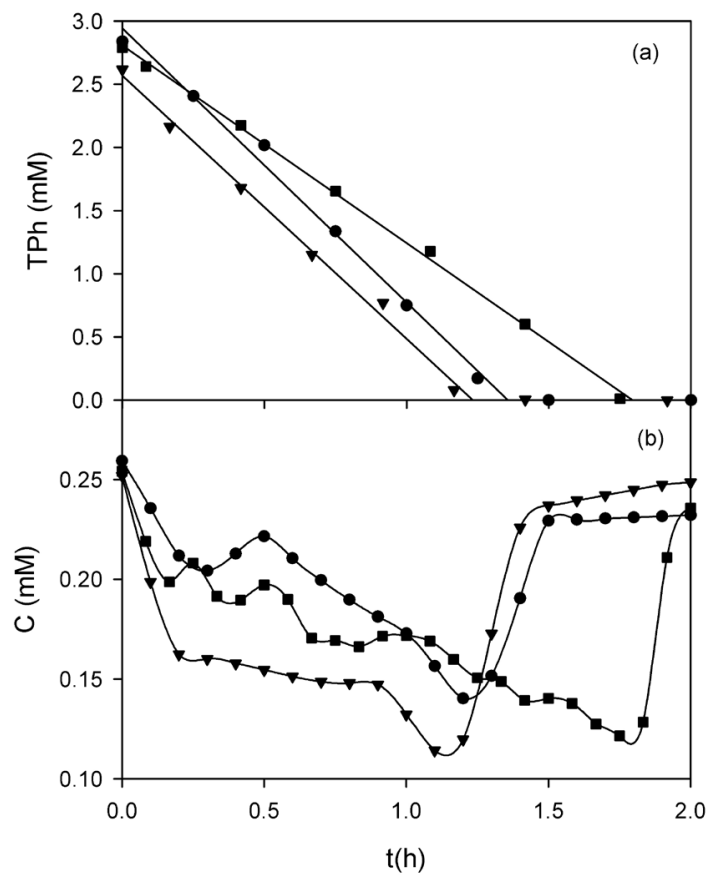

Figure 3

(a) Total phenol (TPh) and (b) dissolved oxygen (C) concentrations as a function of time during fill and draw corresponding to $126(\mathbf{\bullet}), 130(\mathbf{\nabla})$ and 160 ( $\mathbf{\square}$ ) days of operation. Continuous lines in (a) indicate the linear regressions.

concentration $(X)$ increased about $17 \%$ with respect to the initial value (from 1.8 to $2.1 \mathrm{~g} \cdot \ell^{-1}$ TSS), the change of $R_{O 2}$ values could not be attributed to the increment of biomass but to an intrinsic feature of the phenol biodegradation kinetics, such as the inhibition of $R_{\mathrm{O} 2}$ by phenol.

Figure 2 shows that the plot of $s C O D$ as a function of $T P h$ was a straight line with slope $=218 \mathrm{~g} \mathrm{COD} \cdot \mathrm{mol}^{-1} \mathrm{TPh}$; because this slope value is close to the theoretical oxygen demand of phenol (e.g., $224 \mathrm{~g} \mathrm{COD} \cdot \mathrm{mol}^{-1}$ phenol), it was concluded that no partial oxidation products of phenol were released during its degradation. When the phenol was depleted, the lowest $s C O D$ concentration was about $71 \mathrm{mg} \cdot \ell^{-1}$; this background $s C O D$ value was attributed to the presence of microbial soluble products (Xie et al., 2012).

Figure 3 shows several examples of total phenols $(T P h)$ and dissolved oxygen $(C)$ concentrations as a function of time 

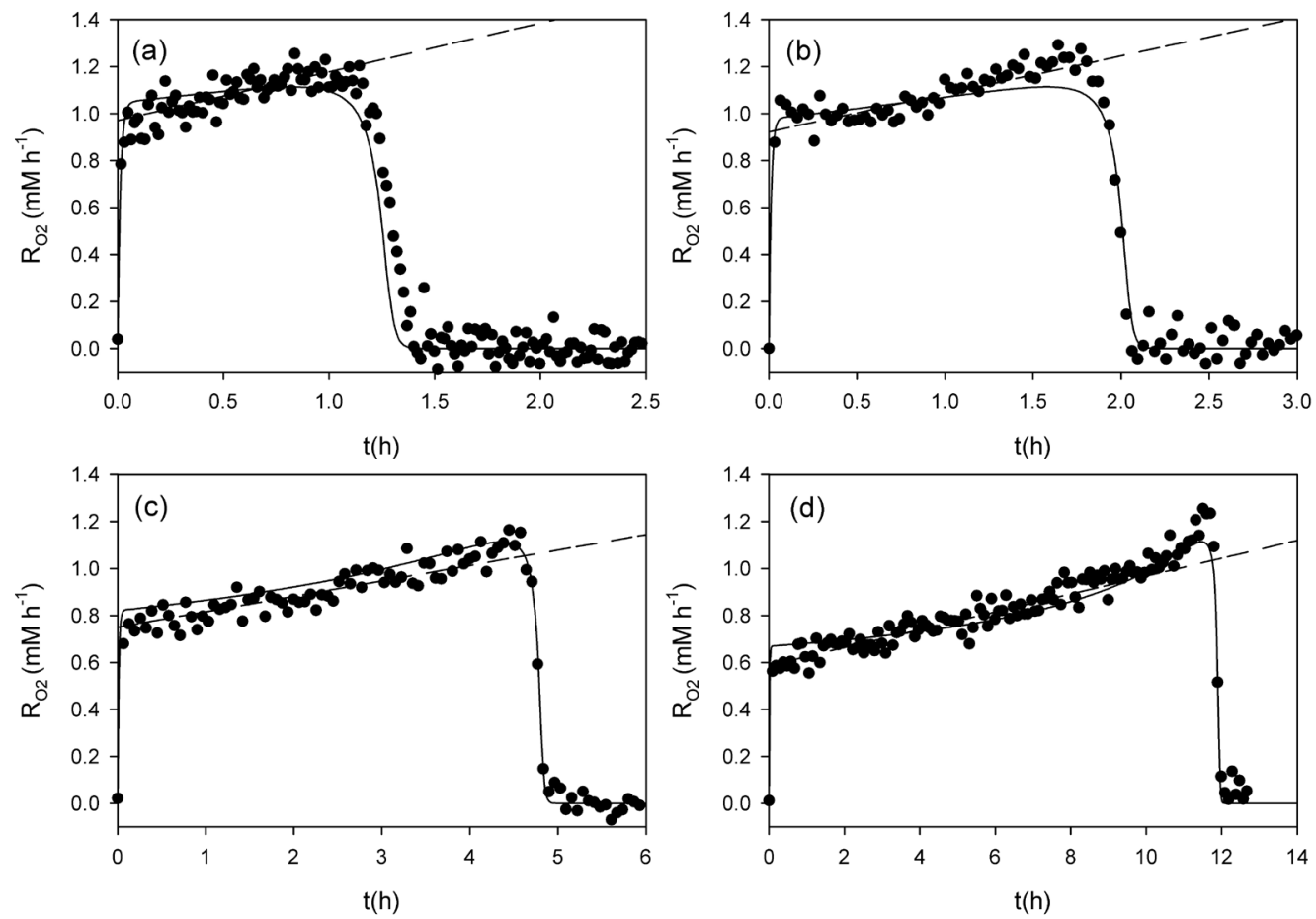

Figure 4
Oxygen uptake rates $\left(R_{\mathrm{O} 2}\right)$
as a function of time for
different initial phenol concentrations (in mM): (a) 0.53, (b) 1.06, (c) 2.12, (d) 5.32 .

Continuous lines indicate the proposed model. Dashed lines indicate the regression line used to calculate the initial oxygen uptake rate $\left(R_{\text {o2o }}\right)$. In these experiments the biomass concentration was $0.7 \mathrm{~g} \cdot \ell^{-1} \mathrm{TSS}$.
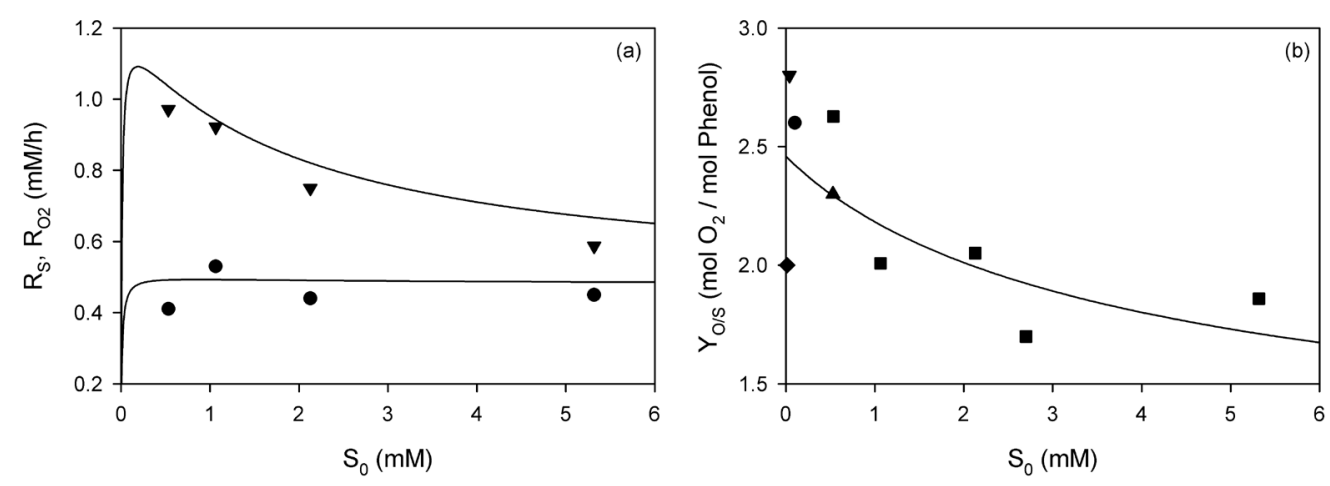

Figure 5

Effect of the initial phenol concentration ( $S_{\text {f }}$ on (a) phenol $\left(R_{s^{\prime}}\right.$ circles) and oxygen ( $R_{0 y}$ triangles) consumption rates (a) and on (b) the overall oxidation coefficient $\left(Y_{0 / S}\right)$ measured in this work (squares) and by other authors: Chudoba et al. (1985) (๑), Orupold et al. (2001) ( $\mathbf{\nabla})$, Contreras et. al (2008) (4), Lepik and Tenno (2011) (\$). Solid lines indicate the results obtained by the proposed model using the coefficients shown in Table 1.

during a fill and draw cycle with phenol. In all cases, a linear decrease of TPh concentration was obtained (Fig. 3a). Taking into account that $C$ values ranged between 0.10 and $0.25 \mathrm{mM}$ (Fig. 3b), these results suggest that within the tested conditions the phenol consumption rate $\left(R_{S}\right)$ was not affected by the dissolved oxygen concentration. Figure 3 also shows that the time at which phenol is depleted $\left(t_{F}\right)$ is similar to the time at which $C$ begins to increase; thus, the increase of $C$ can be used as an indication of substrate depletion. Buitron et al. (2005) developed a control strategy to optimise the reaction time of a SBR based on the DO profile; according to those authors, the time at which the substrate is completely consumed $\left(t_{F}\right)$ can be assessed by the increase in DO.

\section{Effect of the initial phenol concentration on the biodegradation kinetics}

Open respirometer experiments were performed in order to study the effect of initial phenol concentration on respiration rate and on oxygen consumed during phenol biooxidation. Figure 4 shows that for all the tested initial phenol concentrations $\left(S_{0}=0.53\right.$ to $\left.5.3 \mathrm{mM}\right)$, after a start-up period $R_{\mathrm{O} 2}$ increased almost linearly as a function of time and then decreased to values close to zero due to substrate depletion. According to
Fig. 3, the time at which the substrate is completely consumed $\left(t_{F}\right)$ can be assessed by the increase in DO; based on these $t_{\mathrm{F}}$ values, average substrate consumption rates $\left(R_{\text {S-ave }}\right)$ corresponding to different initial phenol concentrations were calculated as the ratio $S_{0} / t_{F}$. Figure 5 a shows that $R_{\text {S-ave }}$ values were constant as a function of the initial phenol concentration $\left(S_{0}\right)$, suggesting Monod type kinetics for the removal rate of $T P h\left(R_{S}\right)$. This result is in accordance with the linear decrease of $T P h$ and $s C O D$ depicted in Figs. 1a and 3a. Besides, from the extrapolation of $R_{\mathrm{O} 2}$ to time zero (Fig. 4 ), initial $R_{\mathrm{O} 2}$ values $\left(R_{\mathrm{O} 20}\right)$ corresponding to the different initial phenol concentrations can be obtained. Figure 5 a shows that $R_{020}$ decreased as $S_{0}$ increased, suggesting a Haldane dependence of $R_{\mathrm{O} 2}$ as a function of $S$. Note that if $R_{S}$ follows the Monod equation and $R_{\mathrm{O} 2}$ obeys a Haldanetype dependence with respect to $S$, then the oxidation coefficient (e.g., the amount of oxygen consumed per unit of substrate oxidised) must be a function of $S_{0}$, rather than a constant.

Based on the $R_{\mathrm{O} 2}$ profiles corresponding to different $S_{0}$ values (Fig. 4), maximum values for the oxygen consumed $\left(O C_{m}\right)$ were calculated using Eq. (2). Figure $5 \mathrm{~b}$ shows that the overall oxidation coefficient $\left(Y_{O / S}\right)$ decreased as $S_{0}$ increased, confirming that the amount of oxygen consumed per unit of substrate oxidised was a function of $\mathrm{S}_{0}$. The range of $Y_{O / S}$ values corresponding to phenol obtained in the present work (1.9-2.6 mol 
$\mathrm{O}_{2} \cdot \mathrm{mol}^{-1}$ phenol) was similar to that reported by other authors. Orupold et al. (2001) studied the oxidation of several phenolic compounds by activated sludge; those authors reported a $Y_{O / S}$ value of $2.6 \pm 0.5 \mathrm{~mol} \mathrm{O}_{2} \cdot \mathrm{mol}^{-1}$ phenol. Recently, Lepik and Tenno (2011) studied the aerobic degradation of phenol by activated sludge acclimated to a wastewater of an oil-shale industry; those authors reported a $Y_{O / S}$ value of $2.0 \mathrm{~mol} \mathrm{O}_{2} \cdot \mathrm{mol}^{-1}$ phenol. It should be noted that $Y_{\mathrm{O} / \mathrm{S}}$ values, calculated according to carbon and reduction degree balances applied to biomass growth with phenol as sole carbon source, range between 4.0 and $7.3 \mathrm{~mol} \mathrm{O}_{2} \cdot \mathrm{mol}^{-1}$ phenol (Feitkenhauer et al., 2001; Kumar et al., 2005). These differences suggest that respirometric $Y_{O / S}$ values reflect a partial oxidation of phenol due to the accumulation of metabolic intermediates. Wang and Loh (1999) studied phenol degradation by Pseudomonas putida ATCC 49451; those authors found that the accumulation of metabolic intermediates of phenol inhibited phenol oxidation, especially at high initial phenol concentrations. Similar results were reported by other authors with regard to the accumulation of metabolic intermediates during phenol degradation by activated sludge (Nuhoglu and Yalcin, 2005; Vazquez-Rodriguez et al., 2006, Ben-Youseff and Vazquez-Rodriguez, 2011).

\section{Modelling phenol oxidation by acclimated activated sludge}

The first step in the aerobic degradation pathway of phenol comprises the hydroxylation of phenol by the enzyme phenol 2-monooxygenase (PH2MO). In the present model it was assumed that the total $\mathrm{PH} 2 \mathrm{MO}$ concentration $\left(E_{T}\right)$ is proportional to the biomass concentration $(X)$, being $q_{E}$, the proportionality constant. According to several authors, the catalytic mechanism of PH2MO involves 3 substrates: molecular oxygen, phenol and NADPH. The reaction scheme for PH2MO can be divided into reductive and oxidative half-reactions. During the reductive step, after the phenol binding, the oxidised form of the enzyme $\left(E_{o x} S\right)$ is reduced by NADPH, NADP ${ }^{+}$leaves the enzyme to produce an intermediary complex $E_{r e d} S$. In the oxidative half-reaction, molecular oxygen reacts with $E_{\text {red }} S$, phenol $(\mathrm{S})$ is hydroxylated to catechol $(\mathrm{SOH})$ and the oxidised form of the enzyme $E_{o x}$ is regenerated (Enroth et al., 1998). Besides, Divari et al. (2003) demonstrate that during the catalytic cycle of $\mathrm{PH} 2 \mathrm{MO}$, the ratio of product formed to NADPH consumed is less than 1. Several authors (Enroth et al., 1998; Divari et al., 2003) have proposed that the mechanism of action of $\mathrm{PH} 2 \mathrm{MO}$ must bifurcate into productive and unproductive paths, which involves the dissociation of $E_{\text {red }} S$ to form free reduced enzyme $\left(E_{r e d}\right)$. The free reduced enzyme is then oxidised by oxygen to produce $E_{o x}$ and $\mathrm{H}_{2} \mathrm{O}_{2}$. Because the decomposition of hydrogen peroxide returns one half of the oxygen consumed, the net result of the unproductive path is the consumption of $0.5 \mathrm{~mol}$ of oxygen. The overall reactions for the productive and unproductive paths are the following:

$$
\begin{aligned}
& \mathrm{S}+\mathrm{NADPH}+\mathrm{O}_{2} \stackrel{\mathrm{R}_{S}}{\longrightarrow} \mathrm{SOH}+\mathrm{NADP}^{+}+\mathrm{OH}^{-} \\
& \mathrm{NADPH}+\frac{1}{2} \mathrm{O}_{2} \stackrel{\mathrm{R}_{\text {unp }}}{\longrightarrow} \mathrm{NADP}^{+}+\mathrm{OH}^{-}
\end{aligned}
$$

Results shown in Fig. 3 suggest that within the experimental conditions the phenol consumption rate was not affected by the dissolved oxygen concentration. Thus, in order to reduce the model complexity it was assumed that, within the tested conditions, both productive and unproductive reaction rates were not affected by the dissolved oxygen concentration. Under these assumptions, the productive path was represented as follows:

$$
\begin{aligned}
& E_{o x}+S \underset{k 2}{\stackrel{k 1}{\longrightarrow}} E_{o x} S \\
& E_{o x} S+N_{r e d} \stackrel{k 3}{\longleftarrow} E_{r e d} S+N_{o x} \\
& E_{r e d} S \stackrel{k_{p}}{\longrightarrow} E_{o x}+S O H
\end{aligned}
$$

To represent the unproductive path, the following reactions were proposed:

$$
\begin{aligned}
& \mathrm{E}_{\text {red }} \mathrm{S} \stackrel{5}{\longleftarrow} \mathrm{E}_{\text {red }}+\mathrm{S} \\
& \mathrm{E}_{\text {red }} \stackrel{\mathrm{k}_{\text {unp }}}{\longrightarrow} \mathrm{E}_{\text {ox }}
\end{aligned}
$$

To express the phenol consumption rate $\left(R_{S}\right)$ as a function of $S$, a steady-state for $E_{o x}, E_{o x} S, E_{r e d} S$ and $E_{r e d}$ was assumed. Under this assumption the phenol consumption rate $\left(R_{S}\right)$ is:

$$
-\frac{d S}{d t}=k_{p}\left(E_{\text {red }} S\right)=R_{S}
$$

Considering Eqs. (3) and (4), the oxygen consumption rate $\left(R_{\mathrm{O} 2}\right)$ is

$$
R_{\mathrm{O} 2}=R_{\mathrm{S}}+\frac{1}{2} R_{\text {unp }}=k_{p}\left(E_{\text {red }} S\right)+\frac{1}{2} k_{\text {unp }}\left(E_{\text {red }}\right)
$$

To further simplify the model, it was assumed that NADPH and $\mathrm{NADP}^{+}$concentrations are nearly constant during the phenol metabolism. Because NADPH and $\mathrm{NADP}^{+}$are intracellular metabolites, their total concentration $\left(N_{T}=N_{\text {red }}+N_{o x}\right)$ is proportional to the biomass concentration $(X)$. If the initial phenol concentration $\left(S_{0}\right)$ is much lower than $N_{T}$, then both NADPH and $\mathrm{NADP}^{+}$concentrations can be considered as constants. Additionally, if $f_{\text {red }}$ is defined as the ratio $N_{r e d} / N_{T}$, then $f_{\text {red }}$ is a constant also. Under this assumption, the following expression can be obtained:

$$
R_{S}=a\left(\frac{b S+S^{2}}{c+d S+S^{2}}\right) x
$$

where the expressions corresponding to the constants $a, b, d$ and $d$ are the following:

$$
\begin{aligned}
& a=k_{p} q_{E}\left\{\frac{N_{T} k_{3} f_{\text {red }}}{k_{p}+N_{T}\left[k_{4}\left(1-f_{\text {red }}\right)+k_{3} f_{\text {red }}\right]}\right\} \\
& b=\frac{k_{\text {unp }}}{k_{6}} \\
& c=\frac{k_{\text {unp }}}{k_{1} k_{6}}\left\{\frac{k_{2}\left(k_{p}+k_{5}\right)+N_{T}\left[k_{2} k_{4}\left(1-f_{\text {red }}\right)+k_{3} f_{\text {red }}\left(k_{p}+k_{5}\right)\right]}{k_{p}+N_{T}\left[k_{4}\left(1-f_{\text {red }}\right)+k_{3} f_{\text {red }}\right]}\right\}
\end{aligned}
$$

$R_{S}$ and $R_{u n p}$ are the rates of the productive and unproductive paths, respectively

$$
d=\frac{k_{2} k_{6} k_{p}+k_{\text {unp }} k_{1}\left(k_{p}+k_{5}\right)+N_{T}\left\{k_{4}\left(k_{2} k_{6}+k_{\text {unp }} k_{1}\right)\left(1-f_{\text {red }}\right)+k_{3}\left[k_{6} k_{p}+k_{1}\left(k_{\text {unp }}+k_{5}\right) f_{\text {red }}\right]\right\}}{k_{1} k_{6}\left\{k_{p}+N_{T}\left[k_{4}\left(1-f_{\text {red }}\right)+k_{3} f_{\text {red }}\right]\right\}}
$$


According to the proposed model, the rate of the unproductive path is:

$$
R_{\text {unp }}=\left(\frac{b e}{S+b}\right) R_{S}
$$

where:

$$
e=\frac{k_{5}}{k_{p}}
$$

The overall oxygen uptake rate during the phenol oxidation $\left(R_{\mathrm{O} 2}\right)$ due to productive and unproductive paths can be calculated by combining Eqs. (11), (12) and (17):

$$
R_{\mathrm{O} 2}=\left[\frac{S+b(1+e / 2)}{S+b}\right] R_{S}
$$

Using software package Gepasi 3, Eqs. (12) and (19) were fitted to the measured $R_{\mathrm{O} 2}$ values as a function of time, corresponding to the different initial phenol concentrations; obtained results are shown in Table 1. Figures 4 and 5 demonstrate that the proposed model adequately represents $R_{\mathrm{O} 2}$ and $R_{S}$ as a function of time for all of the tested initial phenol concentrations. Using the fitted model, $R_{\mathrm{O} 2}$ profiles were calculated for different $S_{0}$ values; then, maximum oxygen consumed $\left(O C_{m}\right)$ was calculated using Eq. (2) and the overall oxidation coefficient $\left(Y_{O / S}\right)$ calculated as the ratio $O C_{m} / S_{0}$. Figure $5 \mathrm{~b}$ shows that $Y_{O / S}$ values obtained from the model were close to the experimental ones, confirming the validity of the developed model.

The fitted model was used to represent the total phenol concentration $(T P h)$ and oxygen uptake rate $\left(R_{\mathrm{O} 2}\right)$ profiles during the fill and draw cycle shown in Fig. 1. In this case, the proposed model adequately predicts the linear decrease of TPh up to its depletion (Fig. 1a). Moreover, Fig. $1 \mathrm{~b}$ shows that $R_{O 2}$ increased as a function of time up to the substrate depletion at $t=2.2 \mathrm{~h}$. Taking into account that these data were not used to fit the model, the agreement shown in Fig. 1 provides a validation of the proposed model.

\section{Analysis of the developed model and comparison with other authors}

Several conclusions arise from the analysis of the proposed model. The first one is that the kinetic coefficients obtained from respirometric data (e.g., $R_{\mathrm{O} 2}$ as a function of $S$ ) characterise the substrate consumption kinetic only if the oxidation coefficient is a constant. Note that the term between brackets in Eq. (19) corresponds to the instantaneous oxidation coefficient, which in fact varies as a function of the actual substrate concentration. For this reason, the overall oxidation coefficient was also a function of the initial phenol concentration.

According to the proposed model, dependences between $R_{\mathrm{O} 2}$ and $R_{\mathrm{S}}$ with $S$ are quite different. While $R_{\mathrm{O} 2}$ as a function of $S$ is close to the Haldane model, a Monod-type equation is more suited to describe the dependency of $R_{S}$ with $S$ (Fig. 5a). In most of the proposed models in the literature, the Haldane equation is an assumption to describe, with more or less accuracy, the biomass growth, phenol and oxygen consumption rates as a function of substrate concentration (Ben-Youssef and Vazquez-Rodriguez, 2011; Christen et al., 2012; Pramparo et al., 2012). Conversely, in the model proposed in the present work the inhibition of the respiration rate for high phenol concentrations arises as a natural consequence of the unproductive path during phenol metabolism (Eqs. (8), (9)). Indeed, in the case of an extremely stable $E_{r e d} S$ complex (e.g., $k_{5} \cong 0$ or $k_{6} \rightarrow \infty$ ), or if the free reduced enzyme $\left(E_{\text {red }}\right)$ could not be oxidised by oxygen (e.g., $k_{\text {unp }} \cong 0$ ), coefficients

\begin{tabular}{|l|l|c|c|}
\hline \multicolumn{4}{|c|}{ TABLE 1 } \\
Coefficients of the proposed model (Eqs. (12), (19)) \\
\hline Coefficient & Units & Value & $\begin{array}{c}\text { Standard } \\
\text { deviation }\end{array}$ \\
\hline a & Mmol TPh $\cdot \mathrm{g}^{-1}$ TSS $\cdot \mathrm{h}^{-1}$ & 0.687 & 0.003 \\
\hline $\mathrm{b}$ & $\mathrm{mM}$ & 2.00 & 0.03 \\
\hline c & $\mathrm{mM}^{2}$ & 0.0205 & 0.0004 \\
\hline $\mathrm{d}$ & $\mathrm{mM}$ & 1.91 & 0.02 \\
\hline e & -- & 2.92 & 0.02 \\
\hline
\end{tabular}

$b$ and $c$ tend to zero (Eqs. (14), (15)), and in this case Eq. (19) of the proposed model can be simplified to obtain the Monod equation.

Several authors have found that the Haldane equation is not always suitable to represent the dependence of growth and substrate consumption rates as a function of $S$. For example, Marrot et al. (2006) studied the growth of activated sludge in phenol as a sole carbon source; these authors found that the specific growth rate increases with phenol concentration and then declines as substrate inhibition became important, in agreement with the Haldane equation. However, according to the data reported by the authors of the abovementioned work, the specific growth rate remains almost constant, about $10 \%$ of the observed maximum, for phenol concentrations higher than $10 \mathrm{mM}$. This behaviour is in agreement with the proposed model; Eqs. (12) and (19) show that both $R_{S}$ and $R_{O 2}$ tend to constant values at high phenol concentrations.

Feitkenhauer et al. (2001) proposed the following equation for the growth rate $\left(R_{X}\right)$ of Bacillus themoleovorans as a function of phenol concentration:

$$
R_{X}=\mu_{\max }\left(\frac{S}{K_{S}+S+S^{2} / K_{i}}\right)(1+S / K) X
$$

This equation is similar to the proposed model; rearranging Eq. (16) the following expression can be obtained:

$$
R_{S}=\left(\frac{a b}{d}\right)\left(\frac{S}{c / d+S+S^{2} / d}\right)(1+S / b) X
$$

From the comparison between Eqs. (20) and (21), it can be concluded that $K=b, K_{s}=c / d$ and $K_{i}=d$; thus, Feitkenhauer et al. (2001) found an empirical equation that is similar to the model developed in the present work.

Several authors have also reported that, for low phenol concentrations, the Monod model with a constant oxidation coefficient $\left(Y_{\mathrm{O} / \mathrm{S}}\right)$ is enough to represent oxygen and phenol consumption kinetics (Chudoba et al., 1985; Orupold et al., 2001; Contreras et al., 2008; Lepik and Tenno, 2011). Under this condition, quadratic terms in Eq. (12) can be neglected, obtaining the following expressions:

$$
\begin{aligned}
& R_{S}=\frac{a b}{d}\left(\frac{S}{c / d+S}\right) X \\
& R_{\mathrm{O} 2}=(1+e / 2) R_{S}
\end{aligned}
$$

Equations (22) and (23) demonstrate that the proposed model tends to the Monod model with a constant oxidation coefficient $\left(Y_{\mathrm{O} / \mathrm{S}}\right)$ at low phenol concentrations. Figure $5 \mathrm{~b}$ shows that $Y_{\mathrm{O} / \mathrm{S}}$ values calculated by using the proposed model at low phenol concentrations are close to the reported values of other authors. Besides, according to Eq. (22), and using the constants shown in Table 1, the phenol saturation constant $\left(K_{S}\right)$ can be calculated as the ratio $c / d=10 \mu \mathrm{M}$. This value is in accordance with 
$K_{S}$ values reported by other authors who have studied phenol biodegradation using respirometric techniques. Chudoba et al. (1985) reported a $K_{S}$ of $14 \mu \mathrm{M}$; Orupold et al. (2001) found $K_{S}$ values ranging from 8 to $16 \mu \mathrm{M}$, corresponding to an activated sludge acclimated to phenolic compounds. Contreras et al. (2008) reported a value for $K_{S}=11 \mu \mathrm{M}$, while Lepik and Tenno (2011) informed $K_{s}=4 \mu \mathrm{M}$. These results demonstrate that the proposed model not only adequately represents the experimental results of the present paper, but also several findings reported by other authors.

\section{CONCLUSIONS}

This work demonstrates that while the phenol removal rate by acclimated activated sludge follows a Monod type kinetics, the oxygen uptake rate obeys a Haldane-type dependence with respect to the phenol concentration; thus, the phenol oxidation coefficient cannot be considered as a constant. A mathematical model based on a simplified version of the catalytic mechanism of the enzyme PH2MO was developed. The proposed model not only adequately represents the experimental results of the present paper, but also predicts several features regarding the aerobic phenol biodegradation that has been reported by other authors. The proposed model can be useful for predicting transient responses, such as substrate and DO concentrations as a function of time, in bioreactors experiencing an overload of phenolic wastewaters.

\section{ACKNOWLEDGMENTS}

The authors gratefully acknowledge the financial support provided by National Council of Scientific and Technical Research (CONICET), National University of La Plata (UNLP) and National Agency for Science and Technology (ANPCyT), Argentina.

\section{REFERENCES}

ALCOCER AS, ORDAZ NR, RAMÍREZ CJ and MAYER JG (2007) Continuous biodegradation of single and mixed chlorophenols by a mixed microbial culture constituted by Burkholderia sp., Microbacterium phyllosphaerae, and Candida tropicalis. Biochem. Eng. J. 37 201-211.

BANERJEE A and GHOSHAL AK (2010) Phenol degradation by Bacillus cereus: Pathway and kinetic modeling. Bioresour. Technol. 101 5501-5507.

BUITRON G, SCHOEB M-E, MORENO-ANDRADE I and MORENO JA (2005) Evaluation of two control strategies for a sequencing batch reactor degrading high concentration peaks of 4-chlorophenol. Water Res. 39 1015-1024.

BEN-YOUSEFF C and VÁZQUEZ-RODRÍGUEZ GA (2011) Modelbased design of different fedbatch strategies for phenol degradation in acclimatized activated sludge cultures. Bioresour. Technol. 102 3740-3747.

BUSCA G, BERARDINELLI S, RESINI C and ARRIGHI L (2008) Technologies for the removal of phenol from fluid streams: A short review of recent developments. J. Hazardous Mater. 160 265-288.

CONTRERAS EM, ALBERTARIO ME, BERTOLA NC and ZARITZKY NE (2008) Modelling phenol biodegradation by activated sludges evaluated through respirometric techniques. J. Hazardous Mater. 158 366-374.

CONTRERAS EM, FERRO OROZCO AM and ZARITZKY NE (2011) Biological Cr(VI) removal coupled with biomass growth, biomass decay and multiple substrate limitation. Water Res. 45 3034-3046.
CHRISTEN P, VEGA A, CASALOT L, SIMON G and AURIA R (2012) Kinetics of aerobic phenol biodegradation by the acidophilic and hyperthermophilic archaeon Slufolobus solfataricus 98/2. Biochem. Eng. J. 62 56-61.

CHUDOBA J, CECH JS, FARKAC J and GRAU P (1985) Control of activated sludge filamentous bulking. Experimental verification of a kinetic selection theory. Water Res. 19 191-196.

DIVARI S, VALETTI F, CAPOSIO P, PESSIONE E, CAVALETTO M, GRIVA E, GRIBAUDO G, GILARDI G and GIUNTA C (2003) The oxygenase component of phenol hydroxylase from Acinetobacter radioresistens S13. Eur. J. Biochem. 270 2244-2253.

EL-NAAS MH, AL-MUHTASEB SA and MAKHLOUF S (2009) Biodegradation of phenol by Pseudomonas putida immobilized in polyvinyl alcohol (PVA) gel. J. Hazardous Mater. 164 720-725.

ENROTH C, NEUJAHR H, SCHNEIDER G and LINDQVIST Y (1998) The crystal structure of phenol hydroxylase in complex with FAD and phenol provides evidence for a concerted conformational change in the enzyme and its cofactor during catalysis. Structure 6 605-617.

FEITKENHAUER H, SCHNICKE S, MULLER R and MARKL H (2001) Determination of the kinetic parameters of the phenol-degrading thermophile Bacillus thermoleovorans sp. A2. Appl. Microbiol. Biotechnol. 57 744-750.

KUMAR A, KUMAR S and KUMAR S (2005) Biodegradation kinetics of phenol and catechol using Pseudomonas putida MTCC 1194. Biochem. Eng. J. 22 151-159.

LEPIK R and TENNO T (2011) Biodegradability of phenol, resorcinol and 5-methyl resorcinol as single and mixed substrates by activated sludge. Oil Shale 28 425-446.

LIN S-H and JUANG R-S (2009) Adsorption of phenol and its derivatives from water using synthetic resins and low-cost natural adsorbents: A review. J. Environ. Manage. 90 1336-1349.

LOBO CC, BERTOLA NC and CONTRERAS EM (2013) Stoichiometry and kinetic of the aerobic oxidation of phenolic compounds by activated sludge. Bioresour. Technol. 136 58-65.

MARROT B, BARRIOS-MARTINEZ A, MOULIN P and ROCHE N (2006) Biodegradation of high phenol concentration by activated sludge in an immersed membrane bioreactor. Biochem. Eng. J. 30 174-183.

NUHOGLU A and YALCIN B (2005) Modelling of phenol removal in a batch reactor. Proc. Biochem. 40 1233-1239.

ORUPOLD K, MASIRIN A and TENNO T (2001) Estimation of biodegradation parameters of phenolic compounds on activated sludge by respirometry. Chemosphere 44 1273-1280.

PRAMPARO L, SUÁREZ-OJEDA ME, PÉREZ J and CARRERA J (2012) Kinetics of aerobic biodegradation of dihydroxybenzenes by a p-nitrophenol-degrading activated sludge. Bioresour. Technol. $11057-62$.

ROS M (1993) Respirometry of Activated Sludge. Technomic Publishing Co., Inc. Basilea, Switzerland. 151 pp.

TZIOTZIOS G, TELIOU M, KALTSOUNI V, LYBERATOS G and VAYENAS DV (2005) Biological phenol removal using suspended growth and packed bed reactors. Biochem. Eng. J. 26 65-70.

VANROLLEHEM PA and GILLOT S (2002) Robustness and economic measures as control benchmark performance criteria. Water Sci. Technol. 45 117-126.

VAZQUEZ-RODRIGUEZ G, BEN-YOUSSEF C and WAISSMANVILANOVA J (2006) Two-step modeling of the biodegradation of phenol by an acclimated activated sludge. Chem. Eng. J. $117245-252$.

WANG S-J and LOH K-C (1999) Modeling the role of metabolic intermediates in kinetics of phenol biodegradation. Enzyme Microbiol. Technol. 25 177-184.

XIE W-M, NI B-J, SEVIOUR T, SHENG G-P and YU H-Q (2012) Characterization of autotrophic and heterotrophic soluble microbial product (SMP) fractions from activated sludge. Water Res. 46 6210-6217. 
http://dx.doi.org/10.4314/wsa.v40i1.15 Available on website http://www.wrc.org.za

ISSN 0378-4738 (Print) = Water SA Vol. 40 No. 1 January 2014 ISSN 1816-7950 (On-line) = Water SA Vol. 40 No. 1 January 2014 